\title{
Solução educacional para o ensino médio? Análise da política de ensino médio integral no estado do Rio de Janeiro
}

\author{
An educational solution for high school? \\ Analysis of the policy of the full-time high school in the state of Rio de Janeiro \\ ¿Solución educativa para la escuela secundaria? \\ Análisis de la política integral de bachillerato en el estado de Río de Janeiro
}

JULIANA RODRIGUES DE OLIVEIRA SOUZA Orcid Id: https://orcid.org/0000-0002-1920-7699

Universidade Federal Fluminense

FLAVIA MONTEIRO DE BARROS ARAÚJO

Orcid Id: https://orcid.org/0000-0003-2227-5622

Universidade Federal Fluminense

\begin{abstract}
Resumo: Este artigo tem como objetivo debater a dimensão curricular da política educacional denominada Solução Educacional para o Ensino Médio (SEEM), formulada em 2012, no âmbito da parceria institucional estabelecida entre a Secretaria de Estado de Educação do Rio de Janeiro (SEEDUC/RJ) e o Instituto Ayrton Senna (IAS). O estudo, de caráter qualitativo, recorre à análise documental e examina os marcos legais e documentos oficiais que orientam o desenvolvimento da política pela SEEDUC/RJ e pelo IAS. Tomando como categorias a relação entre o público e o privado na educação, investiga-se o conceito de educação integral da mencionada política que tem como princípios basilares: o protagonismo juvenil, o desenvolvimento de competências cognitivas e socioemocionais para o Século XXI e a flexibilização e integração curricular. A pesquisa busca não perder de vista os aspectos reformistas envolvidos nesse processo de privatização da educação básica que se desenha a partir da parceria entre o poder público, o terceiro setor e a iniciativa privada, assim como as similaridades da política estudada para com o desenho curricular do ensino médio integral proposto pela reforma do ensino médio (Lei n. 13.415/2017).
\end{abstract}

Palavras-chave: Educação Integral; Ensino Médio; Política Educacional; Políticas Curriculares.

\begin{abstract}
This article aims to discuss the curricular dimension of the educational policy called Educational Solution for Secondary Education (SEEM), formulated in 2012, within the scope of the institutional partnership established between the State Department of Education of Rio de Janeiro (SEEDUC/RJ) and the Ayrton Senna Institute (LAS). The qualitative study uses documentary analysis and examines the legal frameworks and official documents that guide policy development by SEEDUC/RJ and IAS. Taking the relationship between the public and the private in education as categories, we investigate the concept of integral education of the aforementioned policy that has as its basic principles: youth protagonism, the
\end{abstract}


development of cognitive and socioemotional skills for the 21st Century, and the flexibility and curricular integration. The research seeks not to lose sight of the reformist aspects involved in this privatization process of basic education that is drawn from the partnership between the public authorities, the third sector, and the private sector, as well as the similarities of the studied policy with the curriculum design of secondary education proposed by the reform of secondary education (Law No. 13,415/2017).

Keywords: Integral Education; Secondary education; Educational politics; Curriculum.

Resumen: Este articulo tiene como objetivo discutir la dimensión curricular de la política educativa denominada Solución Educativa para la Educación Secundaria (SEEM), formulada en 2012, en el ámbito de la alianza institucional establecida entre la Secretaría de Educación del Estado de Rio de Janeiro (SEEDUC / RJ) y el Instituto Ayrton Senna (LAS). El estudio cualitativo utiliza análisis documental y examina los marcos legales y documentos oficiales que guian el desarrollo de politicas de SEEDUC / RJ e LAS. Tomando como categorías la relación entre lo público y lo privado en educación, investigamos el concepto de educación integral de la referida politica que tiene como principios básicos: el protagonismo juvenil, el desarrollo de habilidades cognitivas y socioemocionales para el siglo XXI y la flexibilidad y integración curricular. La investigación busca no perder de vista los aspectos reformistas involucrados en este proceso de privatización de la educación básica que se deriva de la alianza entre las autoridades públicas, el tercer sector y el sector privado, así como las similitudes de la política estudiada con el diseño curricular. de la educación secundaria propuesta por la reforma de la educación secundaria (Ley $N^{\circ} 13.415$ / 2017).

Palabras clave: Educación Integral; Escuela secundaria; Política educativa; Políticas curriculares.

\section{INTRODUÇÃO}

O estudo em tela busca analisar a dimensão curricular da política educacional da rede pública estadual de educação do Rio de Janeiro denominada "Solução Educacional para o Ensino Médio". Pautada em um conceito específico de educação integral, a política baseia-se em três princípios: protagonismo juvenil; uma matriz para desenvolvimento de competências para o século XXI que articulam aspectos cognitivos e socioemocionais e estratégias de organização integradas e flexíveis para o currículo escolar (INSTITUTO AYRTON SENNA, 2015, p. 3). Problematiza-se, no texto, além dos elementos curriculares pertinentes, a formulação da política pública pelo Instituto Ayrton Senna (IAS) ${ }^{1}$, um ator do terceiro setor que atuou com financiamento do setor privado na elaboração de uma proposta para educação pública estadual.

1

O Instituto Ayrton Senna é uma organização da sociedade civil sem fins lucrativos, que tem como objetivo "dar a crianças e jovens brasileiros oportunidades de desenvolver seus potenciais por meio da educação de qualidade” (INSTITUTO AYRTON SENNA, 2019). 
O percurso metodológico da pesquisa envolveu diversas etapas tais como a análise bibliográfica e documental. A investigação buscou dialogar com as contribuições teóricas de Adrião (2018) Peroni e Adrião (2011), Ball (2012), Ramos (2001), Kuenzer (2006) e Freitas (2012; 2018) que destacam em seus estudos o avanço de processos de privatização da educação pública e o protagonismo de institutos privados na definição de políticas educacionais.

Assume-se neste artigo a perspectiva sobre a pesquisa documental, conforme salienta Pádua (1997). O autor assinala as vantagens da metodologia para a análise de documentos contemporâneos ou retrospectivos e categorização do objeto a partir do referencial analítico, permitindo comparar fatos e estabelecer ligações e divergências. Seguindo por este caminho metodológico (SÁ-SILVA; ALMEIDA e GUINDANI, 2009), compartilham-se os critérios utilizados para selecionar, categorizar e examinar as informações que presentes nos documentos.

A pesquisa bibliográfica procurou rastrear estudos sobre temáticas importantes para este trabalho - ensino médio; educação integral; políticas curriculares; público e privado na educação. Na sequência, realizou-se o levantamento de documentos oficiais que orientaram o desenvolvimento do Programa de Ensino Médio Integral do estado do RJ, como manuais, informativos, orientações e programas ${ }^{2}$. Estes documentos, valiosos para compreensão da política, foram produzidos pelo Instituto Ayrton Senna (IAS) em parceria com a Secretaria de Estado de Educação do Rio de Janeiro (SEEDUC/RJ), a Companhia de Desenvolvimento Industrial do Estado do Rio de Janeiro (CODIN) e Procter \& Gamble $^{3}$ (P\&G); e efetuou-se, ainda, o exame de legislações definidoras de estratégias, matrizes curriculares para o ensino médio integral, tanto de âmbito estadual como federal, no período focalizado pela pesquisa (2014 e 2017), conforme quadro 1.

2 INSTITUTO AYRTON SENNA. Resumo Executivo, Caderno 1: Diretrizes para a política de educação integral solução educacional para o ensino médio. SP: IAS, 2014.

INSTITUTO AYRTON SENNA, Modelo Pedagógico, Caderno 2: Princípios, metodologias integradoras e avaliação da aprendizagem. Diretrizes para a política de educação integral solução educacional para o ensino médio. SP: IAS, 2015.

INSTITUTO AYRTON SENNA, Modelo Pedagógico, Caderno 3: Núcleo Articulador. Diretrizes para a política de educação integral solução educacional para o ensino médio. SP: IAS, 2015a.

INSTITUTO AYRTON SENNA, Material de divulgação da Solução Educacional para o Ensino Médio. Inovação: A escola inovadora que se tornou lei e chegou à sala de aula e à vida. s/d,a.

INSTITUTO AYRTON SENNA, Material de divulgação da Solução Educacional para o Ensino Médio. Validação: Uma proposta de educação integral para todas as escolas. s/d, b.

INSTITUTO AYRTON SENNA, Material de divulgação da Solução Educacional para o Ensino Médio. Integração: Um currículo estruturado para desenvolver competências. s/d, c.

3 Procter \& Gamble Company é uma corporação multinacional americana de bens de consumo sediada no centro de Cincinnati, Ohio, fundada em 1837. 
A análise dos documentos oficiais e normas legais possibilitou a definição de categorias analíticas, entre estas: educação integral; currículo flexível e integrado e competências. Posteriormente, foi realizada a produção dos dados a partir dos aportes teórico-analíticos da pesquisa que apontaram para a existência de processos de privatização da educação básica (ADRIÃO, 2018) e de reforma empresarial da educação (FREITAS, 2018).

\section{Quadro 1 - Legislações referentes às políticas e matrizes curriculares no âmbito estadual e federal relevantes para o estudo da SEEM}

\begin{tabular}{|c|c|c|c|}
\hline Abrangência & Instância & Norma & Descrição \\
\hline Estadual & $\begin{array}{l}\text { Conselho Estadual de } \\
\text { Educação do RJ (CEE/RJ) }\end{array}$ & $\begin{array}{l}\text { Deliberação n. } \\
344 / 2014\end{array}$ & $\begin{array}{l}\text { Define a diretriz operacional para implantação } \\
\text { do currículo do ensino médio integral na rede } \\
\text { estadual de ensino. }\end{array}$ \\
\hline Estadual & $\begin{array}{l}\text { Secretaria de Estado de } \\
\text { Educação do Rio de Janeiro } \\
\text { (SEEDUC/RJ) }\end{array}$ & $\begin{array}{l}\text { Resolução n. } \\
5172 / 2014\end{array}$ & $\begin{array}{l}\text { Estabelece a Diretriz para a implantação das } \\
\text { matrizes curriculares para a educação básica nas } \\
\text { Unidades escolares de Ensino Médio Integrado à } \\
\text { Educação Profissional. }\end{array}$ \\
\hline Estadual & $\begin{array}{l}\text { Secretaria de Estado de } \\
\text { Educação do Rio de Janeiro } \\
\text { (SEEDUC/RJ) }\end{array}$ & $\begin{array}{l}\text { Resolução n. } \\
5424 / 2016\end{array}$ & $\begin{array}{c}\text { Institui a diretriz para implantação do currículo } \\
\text { para as Unidades escolares da Educação Básica } \\
\text { do RJ e Institui os programas: Dupla Escola e } \\
\text { o Solução Educacional para o Ensino Médio } \\
\text { (SEEM). }\end{array}$ \\
\hline Federal & Governo Federal & $\begin{array}{l}\text { Medida provisória } \mathrm{n} . \\
746 / 2016\end{array}$ & $\begin{array}{l}\text { Institui a Política de Fomento à Implementação } \\
\text { de Escolas de Ensino Médio em Tempo Integral } \\
\text { - EMTI. }\end{array}$ \\
\hline Federal & Governo Federal & Lei n. 13.415/2017 & $\begin{array}{l}\text { Política de Fomento à Implementação de Escolas } \\
\text { de Ensino Médio em Tempo Integral - EMTI. }\end{array}$ \\
\hline Estadual & $\begin{array}{l}\text { Secretaria de Estado de } \\
\text { Educação do Rio de Janeiro } \\
\text { (SEEDUC/RJ) }\end{array}$ & $\begin{array}{l}\text { Resolução n. } \\
5508 / 2017\end{array}$ & $\begin{array}{c}\text { Implanta o Programa de Ensino Médio em Tempo } \\
\text { Integral - EMTI na Rede Estadual de Educação } \\
\text { do RJ. }\end{array}$ \\
\hline
\end{tabular}

Fonte: Elaboração própria (2020).

\section{ENSINO MÉDIO, POLÍTICAS CURRICULARES E EDUCAÇÃO INTEGRAL NO ERJ: BREVE RETROSPECTO}

Nas últimas décadas, assiste-se a um intenso movimento de reformas no campo educacional brasileiro que buscaram reorganizar a educação básica. No que se refere ao ensino médio, elas buscaram responder às expressivas dificuldades evidenciadas nas taxas de desempenho, reprovação, abandono e evasão (SHIROMA, MORAES e EVANGELISTA, 2011; CURY, 1998). Para tanto, no período que se segue à aprovação da Lei de Diretrizes e Bases (LDB/96) n. 9394/1996, diversas políticas foram formuladas pelo governo federal com o objetivo de enfrentar graves problemas, identificados na oferta e desenvolvimento do ensino médio. A necessidade de expansão das vagas, considerando a 
obrigatoriedade estabelecida com a emenda constitucional n.59/2009 e melhoria nas graves taxas de aprovação ${ }^{5}$ e rendimento, evidenciadas pelo censo escolar, motivaram a formulação de programas que impactaram a organização dos currículos, a carga horária, a formação dos professores e a articulação com o trabalho na última etapa da educação básica ${ }^{6}$. Estas propostas, desenvolvidas no âmbito do Ministério da Educação, colocaram questões para os sistemas de ensino estaduais que, por meio da adesão aos programas federais, buscaram captar apoio técnico e financeiro para o desenho de programas locais.

O Estado do Rio de Janeiro, foco de nossa análise, desde a retomada do ensino médio integrado à formação profissional, possibilitada pelo Decreto n. $5.154^{7}$, já discutia a ampliação das escolas de tempo integral ${ }^{8}$ de forma cada vez mais expressiva. Após a adesão ao projeto federal de Ensino Médio integrado à Educação Profissional, a Rede Pública Estadual do Rio de Janeiro elaborou propostas para funcionamento inicial de $4 \operatorname{cursos}^{9} \mathrm{em} 2007$. Esta experiência com o ensino médio integrado na Rede Estadual não conseguiu prosperar em todas as unidades.

A mudança nos rumos acontece a partir de 2008, com a realização da primeira parceria com uma empresa privada para oferta do ensino médio integrado à educação profissional no RJ. Afinados com o discurso gerencial, a SEEDUC/

4 Que trata da obrigatoriedade da educação básica e gratuita dos 4 (quatro) aos 17 (dezessete) anos de idade, "assegurada inclusive sua oferta gratuita para todos os que a ela não tiveram acesso na idade própria" (BRASIL, 2009).

$5 \quad$ Ilustrando a ideia, de acordo com o Censo Escolar (2017), a taxas percentuais de abandono desta etapa na rede estadual pública do RJ somada as três séries, ficam em 14,2\% (INEP, 2018), enquanto as taxas de abandono dos 9 (nove) anos do ensino fundamental somadas ficam em 15,6\%. Conclui-se com isso que as taxas de abandono na etapa do ensino médio são mais preocupantes do que as do ensino fundamental.

6 Entre as políticas federais, citamos o Programa de Melhoria e Expansão do Ensino Médio - Projeto Escola Jovem (2000), desenvolvido por com o apoio financeiro do Banco Interamericano de Desenvolvimento (BID) na gestão do então Presidente Fernando Henrique Cardoso (1995-2003), que objetivou a melhoria da qualidade, expansão da cobertura e eficiência do ensino médio, tendo em vista sua importância na contribuição para o desenvolvimento econômico e social do País. E, ainda, a Reforma do Ensino Médio no Governo Michel Temer aprovada pela Lei n. 13.415/2017 que estabeleceu a flexibilização curricular, propondo itinerários formativos e a ampliação da carga horária, sinalizando para adoção do tempo integral na etapa.

$7 \quad$ Em consonância com os compromissos assumidos, logo após a sua posse, o Presidente Luiz Inácio Lula da Silva revogou o Decreto n. 2208/97, sancionado o Decreto n. 5154/2004 que restabeleceu a possibilidade de integração entre o ensino médio e profissional, num mesmo curso, com currículo próprio. A elaboração deste marcava a retomada do debate acerca da educação politécnica compreendida como uma educação destinada à superação da dualidade entre a formação propedêutica e a técnica. (BRASIL, MEC, 2006).

8 Observa-se, que o ERJ possui tradição do estado no desenvolvimento de projetos de educação integral tais a implantação dos Centros Integrados de Educação Pública (CIEP) ao longo dos dois governos de Leonel Brizola (1983 - 1987 e 1991 - 1994).

9 O Programa Ensino Médio Integrado à Educação Profissional foi o primeiro modelo a ser praticado pela rede, em 2007, no Centro Interescolar Estadual Miécimo da Silva, localizado no município de Campo Grande. Os alunos da instituição, que podiam cursar técnico em administração ou edificações, passaram a ter os conhecimentos específicos das áreas em diálogo com aqueles determinados pela base comum. 
RJ estabeleceu um convênio com o Instituto Oi Futuro para implantação de uma escola localizada no município do Rio de Janeiro, que foi denominada Colégio Estadual José Leite Lopes ${ }^{10}$, em homenagem ao cientista, e empreendeu uma experiência de educação em horário integral, buscando articular a preparação para o trabalho, no campo das mídias digitais, com a formação geral.

Neste cenário, em nível federal, foi aprovado o Programa Ensino Médio Inovador (PROEMI), instituído pela Portaria do MEC n. 971/2009, que se configurou como uma importante política pública de fomento à educação integral para a última etapa da educação básica ${ }^{11}$. De acordo com a portaria, o Programa ofereceria apoio técnico e financeiro para unidades federadas trabalharem no desenvolvimento e reestruturação do ensino médio. $\mathrm{O}$ apoio estava condicionado à aprovação de plano de trabalho e celebração de convênio, prevendo a execução direta ou descentralização de recursos (BRASIL, 2009). Com a assinatura do ministro da educação, Fernando Haddad, o PROEMI incentivava a construção de currículos flexíveis e dinâmicos, possuindo:

(...) ênfase nos projetos pedagógicos que promovam a educação científica e humanística, a valorização da leitura, da cultura, o aprimoramento da relação teoria e prática, da utilização de novas tecnologias e o desenvolvimento de metodologias criativas e emancipadoras (BRASIL, 2009).

Com o Programa Dupla Escola, a SEEDUC/RJ passou a promover a educação integral articulada à profissional, tendo como fundamento a legislação que orienta a oferta do ensino médio integrado à formação profissional. A criação do Programa Dupla Escola, embasada na Lei Estadual n. 5068/2007, instituiu o Programa Estadual de Parcerias Público-Privadas (PROPAR). Este programa contou com a participação de empresas que além do desenho de currículos, contrataram instrutores para ministrar as disciplinas profissionalizantes nas escolas estaduais.

Já em 2012, firmou-se a mencionada parceria entre a SEEDUC/RJ e o IAS para a elaboração da política denominada Solução Educacional para o Ensino Médio (SEEM), com o objetivo de ampliar a oferta de ensino médio integral na rede, utilizando essa estratégia para superar o fracasso escolar.

Desde 1994, ano de sua fundação, o IAS atua firmemente no campo educacional em diversos sistemas de ensino com a missão de desenvolver:

soluções educacionais, pesquisas e conhecimentos em pedagogia, gestão

10 Que integra a iniciativa denominada de Núcleo Avançado em Educação (NAVE).

11 Sobre o fomento ao tempo integral nas escolas, assinala-se que a inclusão do ensino médio no FUNDEB - Fundo de Manutenção e Desenvolvimento da Educação Básica e de Valorização dos Profissionais da Educação (Lei n. 11.494/07). 
educacional, avaliação e articulação para que sejam replicáveis em escala. Nossas soluções são levadas às escolas em parceria com as Secretarias de Educação para fortalecer o protagonismo dos educadores e dos alunos no Ensino Fundamental e no Ensino Médio (INSTITUTO AYRTON SENNA, 2019).

O objetivo do instituto é atuar a partir da proposição de soluções para os problemas que as redes públicas enfrentam. O IAS integra uma rede de parcerias que incluem a Organização das Nações Unidas para a Educação, a Ciência e a Cultura (UNESCO) e a Organização para a Cooperação e Desenvolvimento Econômico (OCDE) e conta com apoio de instituições do mercado que contribuem para realizações de ações no campo educativo. $\mathrm{O}$ instituto destaca-se como uma organização social que tem como escopo produzir conhecimento e projetos em consonância com os princípios estabelecidos para suas ações, que segundo discurso de divulgação em seu portal eletrônico ${ }^{12}$, confere centralidade à concepção de educação integral compreendida como estratégia para desenvolver o ser humano em sua plenitude, por meio do trabalho com competências cognitivas e socioemocionais.

A “Solução Educacional para o Ensino Médio" (SEEM), de acordo com os documentos oficiais, foi elaborada agregando "conhecimentos do Instituto Ayrton Senna para a educação do século 21, avanços gerados pela SEEDUC-RJ e concepções inovadoras e marcos legais da educação" (INSTITUTO AYRTON SENNA, 2014, p. 13). Os documentos do instituto citam como referência para a definição do conceito de educação integral da proposta o Relatório da UNESCO (DELORS, 1998) que delimita eixos para educação do século XXI: ser, conhecer, conviver e produzir no mundo.

A política educacional propõe ações que contemplam vários eixos, entre eles a produção da proposta pedagógica; elaboração de guias didáticos e orientações para planos de aula; formação de equipes; ações de implementação e o acompanhamento e avaliação de resultados (INSTITUTO AYRTON SENNA, 2015). O interesse pela dimensão curricular nesse estudo se justifica por sua importância para ações que objetivam reformar a educação básica via etapa do ensino médio. Lopes (2004, p. 111) nos lembra que:

toda política curricular é uma política cultural, pois o currículo é fruto de uma seleção da cultura e é um campo conflituoso de produção de cultura, de embate entre sujeitos, concepções de conhecimento, formas de entender e construir o mundo. 
Segundo a literatura (LOPES e MACEDO, 2011; PERONI e CAETANO, 2012; PERONI e ADRIÃO, 2011; CUNHA, 2011), as definições curriculares constituem uma dimensão importante para os grupos empresariais, pois, possibilitam o controle ideológico do campo educacional, ao mesmo tempo em que proporcionam a produção de uma mão de obra específica para o capital e conseguem manter com o Estado uma relação de interdependência. Através do currículo é possível disseminar valores, práticas e ideologias, formando indivíduos para um mundo guiado pelos interesses do mercado. O currículo do ensino médio, especificamente, possibilita a modelagem de jovens para uma sociedade com ideais liberais, motivados para competição e meritocracia. Nada mais estratégico, em contexto de avanço neoliberal.

Segundo Cunha (2011, p. 605), deve-se:

(...) trazer à compreensão as interferências dos mercados, em suas vertentes ideológica e econômica, nos currículos escolares. Mostramos como a débil autonomia do campo educacional propicia as interferências de diversos agentes, cada qual em busca de vantagens ideológicas, econômicas, frequentemente ambas. Essas interferências, por sua vez, dificultam o avanço do processo de autonomização do campo, acionando-se, em consequência, um movimento de ação recíproca viciosa que não propiciará, certamente, a ampliação nem a melhoria da educação brasileira, especialmente da educação pública, a mais vulnerável às tais interferências mercadológicas.

Nesse sentido, a análise da política "Solução" Educacional, do IAS, sinaliza não apenas para a vulnerabilidade do setor público às interferências do mercado na produção dos currículos, segundo Cunha (2011), como também para as dimensões da privatização da oferta educacional, da gestão da educação pública e do currículo, nos termos de Adrião (2018), com destaque para última. De acordo com a autora, quanto à forma de privatização do currículo:

trata-se de processos pelos quais o setor privado determina para escolas, redes ou sistemas públicos os desenhos curriculares, seja por meio de assessorias, de oferta de tecnologias educacionais e demais insumos curriculares, seja ainda por meio dos Sistemas Privados de Ensino (SPE). Trata-se da privatização dos processos pedagógicos strictu sensu, envolvendo as relações entre professor/a, estudante e conhecimento (ADRIÃO, 2018, p. 12).

A atuação do instituto como produtor de políticas educacionais no Rio de Janeiro, a partir de sua influência e capilaridade, também remete ao conceito de redes, de Ball (2012, p. 29). O autor sustenta, em sua argumentação, a tendência global dos fenômenos de consolidação da entrada de organismos, empresas, 
fundações e institutos filantrópicos na indução de políticas educacionais ${ }^{13}$, atrelando-os a novas formas de governança em rede (BALL, 2012, p. 20). Nesse sentido, estes atores acabam por reterritorializar as políticas, esvaziando as fronteiras entre público, privado, filantrópico, não governamental, que vão sendo constantemente deslocadas e redefinidas.

Freitas (2018), ancorado em Ravich (2011) coloca que comumente os reformadores empresariais da educação são formados por uma "coalizão entre políticos, mídia, empresários, empresas educacionais, institutos e fundações privadas e pesquisadores alinhados com a ideia de que o modo de organizar a iniciativa privada é uma proposta mais adequada para "consertar" a educação".

O autor destaca a presença e centralidade dos grupos que atuam como protagonistas na definição das agendas para as políticas educacionais. A ação destes está conectada ao avanço das políticas de responsabilização, meritocracia e privatização da educação pública. Desta maneira, a responsabilização e a meritocracia viabilizam processos de privatização como os do objeto de nosso estudo, que avançam no campo educacional brasileiro.

\section{ENSINO MÉDIO “SOLUCIONADO”: EDUCAÇÃO INTEGRAL, PROTAGONISMO JUVENIL, FLEXIBILIDADE CURRICULAR E COMPETÊNCIAS SOCIOEMOCIONAIS}

A proposta denominada de Solução Educacional para o Ensino Médio (SEEM), resultante da parceria entre o Instituto Ayrton Senna (IAS) e a SEEDUC/ RJ com a intenção de superar o fracasso escolar da etapa, desde $2014^{14}$, passou a ser considerada como política oficial curricular para o Programa de Educação Integral da rede estadual.

A leitura dos documentos do IAS permite-nos identificar seis eixos norteadores. Três destes estão relacionados ao modelo pedagógico: construção de um conceito único de educação integral; presença de uma matriz flexível de competências cognitivas e socioemocionais; estratégias de organização integrada do currículo. Os outros três dizem respeito ao modelo de implantação: processos de formação e acompanhamento; monitoramento e a avaliação dos processos de implementação; institucionalização da educação integral (INSTITUTO AYRTON SENNA, 2015).

13 A articulação nacional do Movimento Todos pela Educação pode ser usada como exemplo do conceito de redes de Ball (2012).

14 A partir da Deliberação do CEE n. 344/2014, e a Resolução SEEDUC/RJ n. 5424/2016. 
A partir do convênio entre SEEDUC/RJ e IAS, foi implantada, em 2013, uma primeira experiência no Colégio Estadual Chico Anysio (CECA), que integrava o Programa Ensino Médio de Referência. Esta surge inicialmente como "ensino médio experimental", e serviu para validar a proposta na rede (MOEHLECKE, 2018). Em 2016, o referido programa foi levado para mais duas escolas. Segundo os documentos elaborados pelo IAS,

(...) os conhecimentos gerados pela experiência no CECA servem de base para a expansão da iniciativa em toda a rede de ensino estadual. A escola mostrou um desempenho médio $\mathbf{5 0} \%$ melhor nas diversas disciplinas da matriz curricular do ensino médio, comparado às escolas avaliadas pelo Sistema de Avaliação Bimestral do Processo de Ensino e Aprendizagem (Saerjinho), evidenciando que o desenvolvimento de habilidades socioemocionais melhora a performance cognitiva (INSTITUTO AYRTON SENNA, s/d,b, grifos do autor).

No âmbito estadual, portanto, destacam-se duas importantes fontes documentais no conjunto das normas que oficializam a política na rede: a Deliberação do CEE n. 344/2014, e a Resolução SEEDUC/RJ n. 5424/2016. Esses documentos cristalizam as propostas de organização curricular, informada a partir da parceria, além da definição dos modelos de implantação da educação integral no ensino médio na rede. A referida norma considera como argumentos para justificar a modificação na matriz curricular:

(...) no Ensino Médio, em particular, são complexos os desafios que se apresentam, entre os quais os referentes à sua expansão com qualidade, incluindo maciçamente os adolescentes que a ele fazem jus, e que se configura pelo pleno acesso, permanência e desempenho com sucesso em sua aprendizagem (RIO DE JANEIRO, 2014, grifos nossos).

A Deliberação CEE n. 344/2014 é um marco para a instituição da SEEM. O IAS ressalta a importância de sua promulgação. No texto do Caderno Executivo da proposta (INSTITUTO AYRTON SENNA, 2015, p. 04) é afirmado que a:

(...) Secretaria de Estado de Educação do Rio de Janeiro e o Instituto Ayrton Senna vêm validando a iniciativa de forma bem-sucedida em dois modelos de escola, o modelo "Ensino Médio de Referência", que conta com uma organização curricular formulada para abraçar plenamente as inovações propostas, e o modelo "Ensino Médio Nova Geração". (...) Frente à comprovação dos resultados das inovações introduzidas por esta proposta de educação integral, o Conselho Estadual de Educação do Rio de Janeiro reconheceu os esforços empreendidos pela SEEDUC e elaborou instruções normativas (Deliberação n. 344, aprovada pelo Conselho Estadual de Educação em 22 de julho de 2014) que institucionalizaram esta iniciativa pioneira como Diretrizes Operacionais para o Ensino Médio no Estado. 
No documento de apresentação das diretrizes para a política de educação integral do SEEM (INSTITUTO AYRTON SENNA, 2015), o IAS frisa que a concepção de educação integral deve estar ancorada nos seguintes parâmetros:

(...) o conceito de educação integral para o Século XXI exige que seja repensado o propósito da educação e, consequentemente, o currículo ministrado nas escolas. Não basta oferecer mais tempo na escola apenas para aumento do desempenho acadêmico dos estudantes. O propósito da educação integral para o Século XXI é formar para a autonomia, desenvolvendo competências cognitivas e socioemocionais fundamentais para viver no século XXI, possibilitando ao jovem aprender a fazer escolhas na vida (INSTITUTO AYRTON SENNA, 2015, p. 19).

A concepção particular de educação integral da SEEM também inclui a ideia de uma educação para a vida, assim como o conceito de protagonismo juvenil, e de juventudes. Como podemos observar:

(...) Um passo importante nessa direção é compreender que "juventude" é uma categoria socialmente criada, e que é preciso aproximar esse termo do contexto real dos jovens que estão na escola. Afinal, "o que existem são jovens reais, concretos, com os quais lido em minha vida cotidiana. E compreender quem são tais jovens concretos implica compreender essa fase da vida a partir de uma perspectiva complexa, levando em conta um conjunto de variáveis que interferem diretamente na produção social de cada um de nós", afirma Juarez Dayrell (INSTITUTO AYRTON SENNA, 2015, p. 38).

Carrano e Dayrell (2013) assinalam que a modificação do perfil dos estudantes das redes públicas de ensino a partir da LBD n.9394/1996 trouxe para a sala de aula novos desafios e questões. Com a ampliação do acesso ao ensino público, as classes populares começaram a acessar a escola pública, trazendo consigo as disparidades que caracterizam nossa sociedade, como a desigualdade social, a violência, o abismo entre as vivências e capital cultural das diferentes classes sociais, entre outras.

A SEEM produz uma ressignificação da concepção de educação integral para a rede estadual (INSTITUTO AYRTON SENNA, 2014, p. 19), definindo-a portanto: "qualitativamente como o desenvolvimento do ser humano em suas múltiplas dimensões, quer a intelectual e cognitiva, quer a social, emocional e ética, assim como a corporal". Nesse aspecto, a SEEM é uma política educacional que, ao menos em sua concepção, não se furta a reconhecer estas questões. Em seus manuais e documentos norteadores, lê-se sobre a importância do reconhecimento do protagonismo juvenil a necessidade de atualização da concepção de juventudes, 
com a finalidade de colaborar na construção de identidades positivas dos estudantes nas escolas, ao invés de negar suas culturas, formas de sociabilidade e possibilidades de ascensão.

Segundo a literatura (CAVALIERE e COELHO, 2002; COELHO, 2009; NAJJAR, MORGAN e SILVA, 2017), além de um conceito polissêmico, a educação integral configura-se como um campo em permanente disputa, que se relaciona com concepções e matrizes político-filosóficas distintas, ideologicamente (NAJJAR, MORGAN e SILVA, 2017, p. 66). Dito de outra forma, “(...) o conceito é abrangente e, dependendo do contexto em que é usado, revela as disputas que essas concepções e práticas comportam" (CAVALIERE e COELHO, 2002, p. 19).

No bojo da discussão sobre educação integral e tempo integral feita por Coelho (2009), a autora assinala que as tendências para esta modalidade se baseiam, especialmente, sobre três perspectivas - a da escola como proteção social; a de expansão do tempo escolar; e a do currículo integrado (MOEHLECKE, 2018, p. 13). No caso da política educacional estudada, percebe-se que a proposta se pauta na segunda e na terceira, quando se percebe a utilização de estratégias de integração curricular e de expansão do tempo escolar, sendo importante ter em consideração as críticas levantadas à respeito da visão de uma educação integral não vinculada de fato ao desenvolvimento integral do estudante, assim como sobre o desinvestimento da escola como principal espaço educativo (COELHO, 2009).

O material de divulgação da SEEM dá tratamento especial ao currículo integrado da proposta e ressalta, como vantagem da adoção da SEEM pela rede, que: “(...) estratégias educativas inovadoras ganham aplicação concreta e progressiva sem que seja necessário o investimento em tecnologias ou estruturas físicas que estejam muito além das condições atuais das escolas públicas". (INSTITUTO AYRTON SENNA, s/d, a, grifos nossos). O foco é a implantação de uma proposta curricular que, acompanhada de novas práticas docentes, seja capaz de alterar o cenário do ensino médio tornando-o mais atrativo para os jovens e reduzindo a evasão e o fracasso escolar. Expõese nesse trecho a preocupação em esclarecer sobre a não necessidade de novas despesas em decorrência à adesão da política. A intenção é deixar claro que não são necessários investimentos na infraestrutura das escolas. Isso aumenta as chances da responsabilização do sucesso ou fracasso do programa vir a ter caráter individual, seja da rede, da escola ou da própria comunidade escolar.

Como estratégia, o modelo pedagógico da política educacional estudada apresenta uma visão de educação integral, pautada no desenvolvimento de competências, ancorado em Perrenoud (1999), incorporando à concepção da 
política as habilidades essenciais para o convívio, participação social e para o mundo do trabalho, visando ao desenvolvimento de competências e habilidades socioemocionais para o século XXI, assim como a construção de um currículo que converse com os interesses dos jovens.

Encontram-se oito competências socioemocionais que colaboram, segundo a proposta, (INSTITUTO AYRTON SENNA, 2015) para o desenvolvimento da autonomia dos estudantes. Associadas a estas competências, estão dimensões relacionais que cada uma delas engloba e visa despertar seu desenvolvimento. As competências socioemocionais elencadas são: a) autoconhecimento; b) colaboração; c) comunicação; d) responsabilidade; e) abertura para o novo; f) resolução de problemas; g) criatividade; h) pensamento crítico.

Ramos (2001) e Kuenzer (2006) apontam que a pedagogia das competências tem por objetivo a formação do jovem para o capital, a fim de prepará-lo para ser polivalente e flexível, e possa assim estar apto para o trabalho em múltiplas funções, como requerido pelo atual modelo de produção capitalista, tendo ao mesmo tempo disciplina e resiliência para lidar com as contradições que esse modelo apresenta, conformando-se perante o modelo de produção hegemônico.

Discorre-se que, neste caso, a prioridade do desenvolvimento da criatividade e da resolução de problemas da política estudada entra no bojo das competências que fariam dos indivíduos trabalhadores mais competitivos e resignados, uma vez que o desenvolvimento dessas competências é cultivado a partir de uma perspectiva individual. Ao mesmo tempo, no processo educacional, os indivíduos empreendem a dimensão coletiva dessas competências no processo de seu desenvolvimento.

Considerando a questão levantada por Apple (1994, p. 59) sobre o currículo, ele:

(...) nunca é apenas um conjunto neutro de conhecimentos (...) Ele é sempre parte de uma tradição seletiva, resultado da seleção de alguém, da visão de algum grupo acerca do que seja conhecimento legítimo. É produto de tensões, conflitos e concessões culturais, políticas e econômicas que organizam e desorganizam um povo.

No caso da SEEM, em que um agente privado do terceiro setor persegue sua consolidação no campo educacional como indutor de políticas públicas para a educação integral, não poderia ser diferente. Na Deliberação CEE/RJ 
no. $344 / 2014$, art $6^{\circ}$, é apresentado o currículo para o ensino médio integral da rede, dividido entre dois macrocomponentes: áreas do conhecimento e núcleo articulador.

A organização curricular deve ter, como eixos, dois macrocomponentes, a saber: I - Áreas de Conhecimento, para desenvolver e dar sentido, predominantemente, à aprendizagem cognitiva, integrando as disciplinas da Base Nacional Comum; II - Núcleo Articulador, que desenvolve, predominantemente, a aprendizagem sócio emocional dos estudantes, mediante o desenvolvimento do protagonismo e a realização de projetos (RIO DE JANEIRO, 2014a).

A organização curricular, deste modo, é assim definida:

\section{Figura 1 - Currículo da SEEM - Os dois Macro componentes}

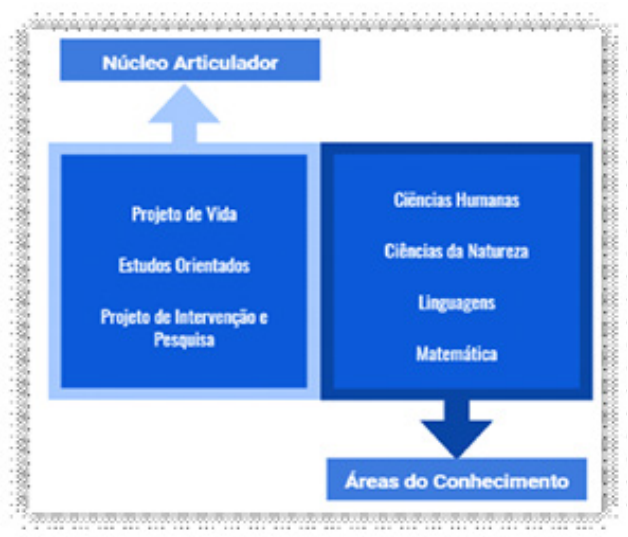

Fonte: Elaborado pelas autoras, a partir de Instituto Ayrton Senna (2015, p.10)

Seguindo este fio, os componentes curriculares da base nacional comum fazem parte das áreas do conhecimento. Já no macrocomponente nomeado "núcleo articulador", que surge como estratégia de flexibilização curricular inovadora, encontram-se os componentes curriculares: projeto de vida, estudos orientados e projeto de pesquisa e intervenção. Segundo os documentos do programa (INSTITUTO AYRTON SENNA, 2015; 2014), estão organizados da seguinte forma: 


\section{Figura 2 - Macrocomponente Núcleo Articulador}

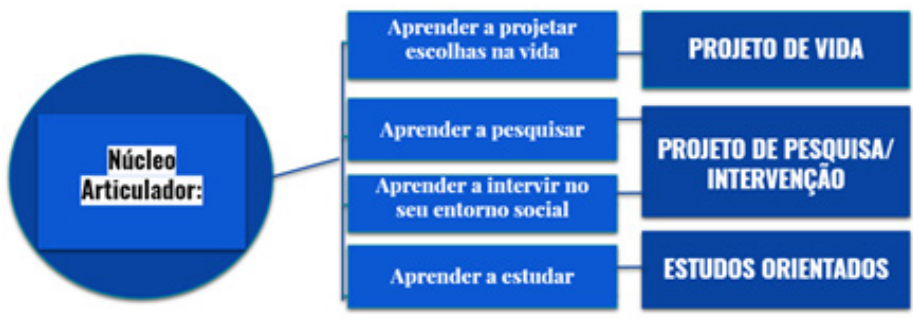

Fonte: Elaborado pelas autoras (2019)

O objetivo declarado do Núcleo Articulador, segundo a análise dos manuais do programa de EMI-RJ, é concretizar os princípios da proposta de educação integral, que envolve a ressignificação do termo, o protagonismo juvenil, a concepção flexível de um currículo integrado, e o desenvolvimento de competências socioemocionais. Esses princípios seriam alcançados através do desenvolvimento de projetos, da personalização do percurso formativo do aluno, do desenvolvimento de competências socioemocionais, do aprendizado por meio da prática e da aplicação do conhecimento em situações concretas.

Esses componentes são estruturados por eixos, relativos às séries do ensino médio, que são: explorar (na $1^{a}$ série), investigar (na $2^{a}$ série), expandir (na $3^{\mathrm{a}}$ série). O projeto de vida tem como pilares a dimensão pessoal, cidadã e profissional do estudante, tendo como finalidade promover a reflexão dos jovens sobre a construção de suas identidades e de seus projetos de vida.

$\mathrm{Na}$ dimensão pessoal, os objetivos versam sobre a compreensão de si mesmo dos estudantes. O itinerário proposto visa colaborar com a identificação de seus interesses e necessidades, com a significação de suas vivências na escola e fora da escola (INSTITUTO AYRTON SENNA, 2015, s/d,a). Na dimensão cidadã, o objetivo é que os estudantes conheçam e compreendam seus direitos e deveres, e, principalmente, reflitam e dialoguem sobre as maneiras que vivenciam o compromisso com o outro e o bem comum (INSTITUTO AYRTON SENNA, 2015). As experiências cotidianas na escola, em especial aquelas que dizem respeito ao convívio e à atuação em times nos projetos e nas aulas, são os focos de significação pelos jovens. Já a dimensão profissional objetiva provocar a reflexão e o diálogo dos estudantes sobre seus interesses em relação à inserção no mundo do trabalho, tendo como ponto de partida os conhecimentos, as habilidades e as competências desenvolvidas ao longo de sua trajetória escolar, familiar e comunitária. Esta dimensão pretende possibilitar que os estudantes 
avaliem e deem significado às experiências vivenciadas na escola, para que possam projetar os próximos passos de formação e/ou início de sua atuação profissional (INSTITUTO AYRTON SENNA, 2015).

Outro componente do Núcleo Articulador, o projeto de pesquisa, tem por objetivo declarado inserir o estudante no campo da pesquisa científica, ensinando métodos e técnicas de sistematização e estimulando a integração dos conhecimentos aprendidos nas disciplinas com os problemas reais que eles identifiquem na comunidade escolar, buscando sua resolução (INSTITUTO AYRTON SENNA, 2015). O projeto de intervenção busca promover a corresponsabilidade pela escola e seu entorno, por meio de projetos que partam do interesse dos estudantes e que contribuam para a transformação do contexto em que estão inseridos. Já o terceiro componente do Núcleo Articulador, os estudos orientados, visa proporcionar momentos para aprender a estudar e a realizar tarefas na escola com orientação de professores (INSTITUTO AYRTON SENNA, 2015).

Em 2017, quando o programa de educação integral do RJ incorporou a reforma do ensino médio ${ }^{15}$, o ERJ realizou uma parceria com o SEBRAE-RJ ${ }^{16}$, a fim de contemplar uma dimensão relativa ao empreendedorismo que o edital demandava.

\section{ENSINO MÉDIO REFORMADO: A SOLUÇÃO EDUCACIONAL PARA O ENSINO MÉDIO E SUA ARTICULAÇÃO COM A LEI 13.415/2017}

A Política de Fomento à Implementação de Escolas de Tempo Integral (EMTI/Reforma do Ensino Médio) foi aprovada com a Lei no. 13.415/2017, após ter sido apresentada à comunidade educacional e à população em geral, via medida provisória ${ }^{17}$. Importa ressaltar que, segundo os documentos consultados, a reforma ancora-se na valorização de uma abordagem que se pretende prática para os estudantes, propondo os chamados itinerários formativos, que sustentam o caráter diversificado do currículo dividido em duas unidades: a parte comum e a flexível. A parte comum, obrigatória para todos os estudantes, é subdividida, por sua vez, em formação geral básica e projeto de vida. A formação geral básica deve ter carga horária máxima de 1.800 horas. Nela estão abrigadas as disciplinas que compõem a BNCC, levando em consideração as competências e habilidades

\footnotetext{
$15 \quad$ Lei $14.415 / 2017$.

16 Serviço Brasileiro de Apoio às Micro e Pequenas Empresas.

17 Medida Provisória n. 746/2016, do governo Temer.
} 
previstas na base para as Áreas do Conhecimento (ciências da natureza, linguagens, matemática e ciências humanas). O projeto de vida concerne à capacidade do estudante de definir objetivos para sua vida pessoal, acadêmica, profissional e cidadã. Essa dimensão deve ser estimulada ao longo de todo o processo de formação geral básica.

Ainda segundo a organização curricular da reforma, na parte flexível do currículo, estão abrigados os chamados itinerários formativos e as unidades eletivas, com carga horária mínima de 1.200 horas. Estas pretendem proporcionar um aprofundamento em uma ou mais Áreas do Conhecimento e/ou na Formação Técnica e Profissional, conforme interesse do estudante e/ou capacidade de oferta de redes/escolas, segundo o material de divulgação da reforma elaborado pelo Instituto Porvir (2018).

Em 2017, a SEEDUC/RJ se inscreveu no edital publicado pelo governo federal que tinha como escopo fomentar a implantação de escolas de ensino médio em tempo integral (EMTI). Instituído pela Lei n. 13.415/2017 e, posteriormente, pela Portaria n. 1.023/2018. O edital apresenta:

(...) A Política de Fomento de que trata o caput prevê o repasse de recursos do Ministério da Educação para os Estados e para o Distrito Federal pelo prazo de dez anos por escola, contado da data de início da implementação do ensino médio integral na respectiva escola, de acordo com termo de compromisso a ser formalizado entre as partes, que deverá conter, no mínimo: I - identificação e delimitação das ações a serem financiadas; II - metas quantitativas; III cronograma de execução físico-financeira; IV - previsão de início e fim de execução das ações e da conclusão das etapas ou fases programadas (BRASIL, 2017).

Essa legislação, de acordo com a retórica governamental, estaria relacionada ao cumprimento do Plano Nacional de Educação - PNE/2014 (Lei n. 13.005/2014) que estabeleceu entre suas metas a de número 6: "oferecer educação em tempo integral em, no mínimo, $50 \%$ (cinquenta por cento) das escolas públicas, de forma a atender, pelo menos, $25 \%$ (vinte e cinco por cento) dos(as) alunos(as) da educação básica" (BRASIL, 2014, p. 28). Percebe-se também, no próprio texto do Plano, que a parceria com o setor privado já é considerada uma estratégia (6.5 - que trata das parcerias com entidades privadas) para o cumprimento da meta.

Em consonância com a SEEM, a proposta do novo ensino médio elaborada pelo MEC, para além da ampliação da carga horária, apresentou como diferencial para a etapa a centralidade do jovem no processo de aprendizagem, o desenvolvimento integral, a formação para a vida no século XXI, a flexibilização e a atualização curricular com base nas áreas do conhecimento. 
É possível notar, também, visões convergentes de educação integral entre os textos da SEEM e da Lei n. 13.415/2017, que, em seu art. 35-A \ $7^{\circ}$, determina que os currículos do ensino médio: “deverão considerar a formação integral do aluno, de maneira a adotar um trabalho voltado para a construção de seu projeto de vida e para sua formação nos aspectos físicos, cognitivos e socioemocionais" (BRASIL, 2017).

\section{CONSIDERAÇÕES FINAIS}

Os debates em torno da disputa entre o público e o privado colocam em oposição diferentes visões sobre a educação pública. De um lado, há o entendimento da educação como um bem público e responsabilidade do Estado; de outro, a visão privada da educação através da gestão empresarial e da promoção de uma lógica liberal de educação como ferramenta para o desenvolvimento econômico.

A proposta do Instituto Ayrton Senna para o ensino médio integral da rede estadual, de acordo com as diretrizes da "Solução Educacional para o Ensino Médio", não se configura apenas como um programa pontual para o Rio de Janeiro. Em seu escopo, estipula-se um plano com metas, condições e estruturas legais que possibilitem a fixação da educação integral, a partir dos moldes da SEEM, como política pública educacional da rede estadual não apenas de um governo. As normas estabelecidas pela Deliberação CEE n. 344/2014 e pela Resolução SEEDUC/RJ n. 5424/2016 apontam nessa direção. Percebe-se, concomitantemente, conforme a literatura aponta à respeito da disputa de sentido no campo educacional, o movimento na busca pela consolidação do viés liberal de educação integral, do Instituto, no campo educacional nesse sentido.

O protagonismo do IAS, um instituto de caráter privado, na produção de políticas para o ensino médio aprofunda a discussão sobre os processos de privatização da educação básica (Adrião, 2018). Nesse sentido, a análise da política "Solução" Educacional, do IAS, sinaliza para as três dimensões da privatização da educação básica (da oferta educacional, da gestão da educação pública e do currículo) nos termos da autora, tendo em vista o papel proeminente deste instituto na definição da política educacional estudada na rede estadual. 
Segundo a análise documental realizada nesta pesquisa, alguns elementos do texto que define a política curricular produzida a partir da parceria IAS/ SEEDUC-RJ/P\&G-Codin, podem ser encontrados também como parte das prescrições para a reforma do ensino médio federal, o que nos permite destacar o protagonismo do Instituto como importante ator no processo de reforma curricular da etapa do ensino médio e importante membro do grupo dos reformadores empresariais da educação, segundo os termos de Freitas (2018). Nesse ensejo, considera-se problemático o deslizamento da responsabilidade da produção e promoção das políticas sociais do Estado para a sociedade civil, pois as agendas políticas e econômicas destes agentes não passam por validação pública e os cidadãos não estão incluídos nos processos decisórios.

\section{REFERÊNCIAS}

ADRIÃO, T. Dimensões e formas da privatização da educação no Brasil: caracterização a partir de mapeamento de produções nacionais e internacionais. Currículo sem Fronteiras, v. 18, n. 1, jan./abr. 2018, pp. 8-28.

APPLE, M. W. A política do conhecimento oficial: faz sentido a ideia de um currículo nacional? In: MOREIRA, A. F. \& SILVA, T. T. (orgs). Currículo, cultura e sociedade. $2^{a}$ ed. São Paulo: Cortez, 1995.

BALL, S. J. Educação Global S.A. Novas redes políticas e o imaginário neoliberal. Ponta Grossa: Editora UEPG, 2012.

BRASIL. Emenda Constitucional N. 59, de 11 de novembro de 2009.

. Lei n. 9.394, de 20 de dezembro de 1996. Estabelece as diretrizes e bases da educação nacional. Diário Oficial da União, Brasília, DF, 23 de dezembro de 1996.

Lei n. 11.494, de 20 de junho de 2007. Regulamenta o Fundo de Manutenção e Desenvolvimento da Educação Básica e de Valorização dos Profissionais da Educação - FUNDEB. Brasilia, DF: Presidência da República, 2007. 
. Ministério da Educação. Portaria n. 971, de 09 de outubro de 2009. Institui o Programa Ensino Médio Inovador - PROEMI. Brasília, DF: MEC, 2009.

Lei $\mathbf{n}^{\circ}$ 13.005, de 25 de junho de 2014. Aprova o Plano Nacional de Educação - PNE e dá outras providências. Brasília, DF: Presidência da República, 2014.

. Lei n. 13.415/2017, de 13 de fevereiro de 2017. Institui a Política de Fomento à Implementação de Escolas de Ensino Médio em Tempo Integral. Brasília, DF: Presidência da República, 2017.

CAVAliERE, A. M. V. e COELHO, L. M. C. C. Educação brasileira e(m) tempo integral. Petrópolis, Vozes, 2002.

CARRANO, P.; DAYRELL, J. (Orgs.). O jovem como sujeito do ensino médio. Curitiba: Ministério da Educação; UFPR, 2013.

COELHO, L. M. C. C. História(s) da educação integral. Em Aberto, Brasília, v. 22, n. 80, p. 83-96, abr. 2009.

CUNHA, L. A. Contribuição para a análise das interferências mercadológicas nos currículos escolares. Revista Brasileira de Educação v. 16 n. 48 set.-dez. 2011.

CURY, C. R. J. O ensino médio no Brasil: histórico e perspectivas. Educação em Revista, Belo Horizonte, 27 jul. 1998.

DELORS, J. Educação: um tesouro a descobrir. Relatório para a UNESCO da Comissão Internacional sobre Educação para o Século XXI. 4a. ed. SP: Cortez; Brasília: MEC: UNESCO, 1998.

FREITAS, L. C. Os reformadores empresariais da educação: da desmoralização do magistério à destruição do sistema público de educação. Educação \& Sociedade, v. 33, n. 119, 2012.

A reforma empresarial da educação: Nova direita, novas ideias. São Paulo: Expressão Popular, 2018. 
INSTITUTO AYRTON SENNA. Material de divulgação da Solução Educacional para o Ensino Médio. Inovação: A escola inovadora que se tornou lei e chegou à sala de aula e à vida. $\mathrm{s} / \mathrm{d}$, a.

- Material de divulgação da Solução Educacional para o Ensino Médio. Integração: Um currículo estruturado para desenvolver competências. s/d, b.

\section{Resumo Executivo, Caderno 1: Diretrizes}

para a política de educação integral solução educacional para o ensino médio. SP: IAS, 2014.

Modelo Pedagógico, Caderno 2: Princípios, metodologias integradoras e avaliação da aprendizagem. Diretrizes para a política de educação integral solução educacional para o ensino médio. SP: IAS, 2015.

Quem somos. São Paulo. Disponível em: https://www.institutoayrtonsenna.org.br/pt-br/quem-somos.html. Acesso em: 10 jan. 2019.

INSTITUTO POVIR. Infográfico elaborado a partir de relatório do Movimento pela Base. Disponível em < http://porvir.org/novo-ensino-medioentenda-os-itinerarios-formativos/> 2018.

KUENZER, A. A educação profissional nos anos 2000: a dimensão subordinada das políticas de inclusão. Revista Educação e Sociedade, Campinas, SP, v. 27, n. 96 - Especial, p. 877-910, out. 2006.

LOPES, A. Políticas curriculares: continuidade ou mudança de rumos?. Rev. Bras. Educ., n. 26, p.109-118, ago, 2004.

LOPES, A; MACEDO, E. Teorias de Currículo. São Paulo: Cortez, 2011.

MOEHLECKE, S. Políticas De Educação Integral Para o Ensino Médio no Rio De Janeiro: Uma ampliação do direito à educação? Currículo sem Fronteiras, v. 18, n. 1, p. 145-169, jan./abr. 2018. 
NAJJAR, J; SILVA, W. C.; MORGAN, K. N. V. Educação integral em São João de Meriti: conceitos em desalinho. Conhecimento \& Diversidade, Niterói, v. 9, n. 17, p. 61-71, jan./jun. 2017.

PERONI, V.; ADRIÃO, T. Análise das consequências de parcerias firmadas entre municípios brasileiros e a Fundação Ayrton Senna para a oferta educacional, (Relatório de pesquisa) 2011.

PERONI, V. M. V; CAETANO, M.R. Redefinições no papel do Estado: Terceira Via, Novo desenvolvimentismo e as parcerias público-privadas em educação. Revista da FAEEBA: Educação e Contemporaneidade. v. 21, n. 38, 2012.

PERRENOUD, P. Construir as Competências desde a escola. Porto Alegre, Artmed, 1999.

RAMOS, M. N. A Pedagogia das competências: autonomia ou adaptação? SP: Cortez, 2001.

RAVITCH, D. National opportunity to learn summit. 2011. Disponível em: https://www.ucc.org/justice/public-education/pdfs/NatlOTL.pdf

RIO DE JANEIRO (Estado). Secretaria de Estado de Educação - SEEDUC. Convênio SEEDUC n. 06/2013. Diário Oficial do Estado do Rio de Janeiro, Rio de Janeiro, RJ, 20 fev. 2013.

. Secretaria de Estado de Educação - SEEDUC Convênio SEEDUC n. 10/2013. Diário Oficial do Estado do Rio de Janeiro, Rio de Janeiro, RJ, 08 mar. 2013.

Conselho Estadual de Educação. Deliberação

CEE n. 344, de 22 de julho de 2014. Define diretrizes operacionais para a organização curricular do Ensino Médio na rede pública de ensino do estado do Rio de Janeiro. Diário oficial do Estado do Rio de Janeiro, Rio de Janeiro, RJ, 15 ago. 2014a. 
Resolução Seeduc n. 5172 De 30 de

dezembro de 2014. Fixa Diretrizes Para Implantação Das Matrizes Curriculares Para Educação Básica Nas Unidades Escolares De Ensino Médio Integrado À Educação Profissional, E Dá Outras Providências. Diário Oficial do Estado do Rio de Janeiro, Rio de Janeiro, RJ, 2014b.

- Resolução Seeduc n. 5424 de maio de

2016. Estabelece O Conceito Para A Implementação Do Programa De Educação Integral, No Âmbito Da Secretaria De Estado De Educação Do Estado Do Rio De Janeiro, e dá outras providências. Diário Oficial do Estado do Rio de Janeiro, Rio de Janeiro, RJ, 3 de Maio de 2016.

- Resolução Seeduc n. 5508 de 01 de fevereiro de 2017. Implanta o Ensino Médio Em Tempo Integral, com Ênfase Em Empreendedorismo Aplicado ao Mundo do Trabalho, nas unidades escolares que menciona, e dá outras providências. Diário Oficial do Estado do Rio de Janeiro, Rio de Janeiro, RJ, 2 de fevereiro de 2017.

Shiroma, E. O.; MORAES, M. C. M.; EVAngelista, O. Política educacional. Rio de Janeiro: Lamparina, 2011.

SILVA, J. R. S.; ALMEIDA, C. D.; GUINDANI, J. F. Pesquisa documental: pistas teóricas e metodológicas. Revista Brasileira de História \& Ciências Sociais Ano I, Número I, Julho de 2009.

\footnotetext{
Juliana Rodrigues de Oliveira Souza

Mestre em Educação pelo Programa de Pós-Graduação em Educação da Universidade Federal Fluminense (UFF) e bacharel em Ciências Sociais pela UFF. Integrante do Núcleo de Estudos e Pesquisas em Gestão e Políticas Públicas em Educação (NUGEPPE/UFF) e do Grupo de Pesquisas em Políticas Públicas em Educação (GRUPPE/UFF). Professora de Sociologia da Secretaria Estadual de Educação do Rio de Janeiro (SEEDUC/RJ), atuando na formação de professores da rede. E-mail: juliana.rosouza@gmail.com
} 


\section{Flavia Monteiro de Barros Araújo}

Doutora em Educação pela Universidade do Estado do Rio de Janeiro (2006), com pós-doutorado pelo Programa de Pós-Graduação em Educação, PROPED/ UERJ (2009). É Professora adjunta da Faculdade de Educação (UFF), Secretária de Educação no Município de Niterói/RJ (SME/Niterói) e membro do Conselho Estadual de Educação (CEE/RJ). Integrante do Núcleo de Estudos e Pesquisas em Gestão e Políticas Públicas em Educação (NUGEPPE/UFF) e do Grupo de Pesquisas em Políticas Públicas em Educação (GRUPPE/UFF). E-mail: fmbaraujo@hotmail.com

Recebido em 07/07/2020

Aprovado em 20/10/2020 